HOLLEMAN / RICHTE R

ORGANISGHE CHEMIE 

A. F. HOL L EMA N

L E H B U C H D E C H E I E

Zweiter Teil

\title{
Organische Chemie
}

\author{
Bearbeitet von
}

F R IE D R I C H R I H T E R

29. und 30., durchgesehene und erweiterte Auflage mit 108 Figuren

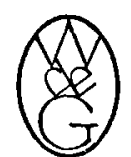

1953

WA LTER DE GRUYTER \& CO. vormals G. J. Góschen'sche Verlagshandlung J. Guttentag. Verlagsbuchhandlung • Georg Reımes Karl J Trübner . Vert \& Comp.

B E R L I N W 5 
Alle Rechte, auch die des auszugsweisen Nachdrucks, der photomechanischen Wiedergabe, der Herstellung von Mikrofilmen und der Übersetzung vorbehalten.

Copyright 1953 by WALTER DE GRIYTER \& CO., vormals G. J. Göschen'sche V'erlagshandlung - J. Guttentag, Verlagsbuchhandlung

- Georg Reimer - Karl J. Trübner - Veit \& Comp, BERLIN W 33 Archiv-Nr. 523253

Printed in Germany

SATZ: Walter de Gruyter \& Co., Berlin W 35

DRUCK : Otto von Holten und Hayns Erben. Berlin. 